\title{
Turnal

\section{Pengaruh Memorable Tourism Experience Terhadap Revisit Intention di Objek Wisata Pantai Air Manis Padang}

\author{
Rezvianny Dianty ${ }^{1}$, Youmil Abrian ${ }^{2}$, Rian Surenda ${ }^{3}$ \\ ${ }^{1}$ Universitas Negeri Padang \\ ${ }^{2}$ Universitas Negeri Padang \\ ${ }^{3}$ Universitas Negeri Padang
}

Email : abrian.yomil@fpp.unp.ac.id

\begin{abstract}
ABSTRAK
Penelitian ini dilatarbelakangi oleh keingintahuan tentang kondisi wisatawan yang berkunjung ke Pantai Air Manis Padang dan telah mencapai fase memorable tourism experience (pengalaman wisatawan yang mengesankan) sehingga berdampak pada revisit Intention (minat kunjung ulang). Penelitian ini berjenis kuantitatif dengan pendekatan assosiatif kausal. Populasi pada penelitian ini ialah wisatawan yang berlibur ke daya tarik Pantai Air Manis Padang. Teknik sampling menggunakan purposive sampling dengan menggunakan kriteria tertentu sehingga didapatkan 98 sampel.. Instrumen dalam penelitian menggunakan angket tersusun sesuai skala likert yang di uji validitas lalu reliabilitasnya. Pengujian hipotesis penelitian menggunakan analisis regresi linear.

Berdasarkan hasil pengujian hipotesis, didapatkan nilai R Square 0,143 yang disimpulkan pengaruh pada variabel memorable tourism experience terhadap revisit intention sebanyak $14,3 \%$ serta $85,7 \%$ ditentukan oleh variabel lain. Selanjutnya diperoleh nilai F hitung sebesar 15,976 dengan sig. $0.000<0.05$, maka disimpukan bahwa variabel memorable tourism experience $(\mathrm{X})$ berpengaruh secara signifikan terhadap variabel revisit intention $(\mathrm{Y})$. Jumlah nilai t hitung pada penelitian ini bernilai 3,997 dengan sig. $0.000<0.05$ untuk variabel memorable tourism experience. Koefisien regresi ialah 0.181 dengan nilai sig. $0.000<0.05$. Maknanya setiap penambahan 1 satuan memorable tourism experience akan menambahkan 0.181 revisit intention.
\end{abstract}

Kata kunci:Memorable Tourism Experience, Revisit Intention,Pantai Air Manis Padang. 


\section{PENDAHULUAN}

Sektor pariwisata Indonesia memiliki ciri khas serta keunikan yang beragam.Sektor pariwisata Indonesia apabila dikembangkan dengan baik maka pariwisata Indonesia akan semakin maju sehingga dapat memberikan manfaat bagi warga negara Indonesia. Kemajuan sektor pariwisata akan berdampak pada luasnya lapangan pekerjaan dan dapat meningkatkan pendapatan penghasilan pemerintah dan masyarakat sekitar tempat wisata. Salah satu langkah sektor pariwisata dalam meningkatkan pendapatan dengan memberikan kesan baik sehingga menjadi kenangan berwisata yang tak terlupakanbagi wisatawan.

Salah satu daerah yang banyak dikunjungi di Sumatera Barat adalah Kota Padang.Kota Padang memiliki jenis wisata yang beragam contohnya wisata air, wisata yang alami, wisata kebudayaan minangkabau, wisata bersejarah, dan wisata makanan dan mainuman. Wisata air yang terkenal di Kota Padang yaitu Pantai Air Manis.

Pantai Air Manis ialah wisata terbaik di Kota Padang yang memiliki ketinggian 4 meter (diatas permukaan laut) dan didukung oleh kawasan sekitar yang dikelilingi oleh wilayah perbukitan yang indah. Luas lahan wisata Pantai Air Manis adalah \pm 10 Ha. Fasilitas yang dimiliki oleh objek wisata Pantai Air Manis berupa lahan parkir, gazebo, lokasi perdagangan (makanan, minuman, dan souvenir), musala, WC umum, taman, posko keamanan, tempat penyewaan olahraga air dan pantai, penyewaan tikar, dan home stay. Dinas Pariwisata dan Kebudayaan Kota Padang dan Perusda Padang Sejahtera Mandiri (PSM) ditunjuk sebagai pengelola pantai ini. Keistimewaan Pantai Air Manis Padang adalah adanya cerita rakyat Minangkabau yaitu legenda batu Malin Kundang yang merupakan anak durhaka kepada ibunya dan dikutuk menjadi batu.

Minat kunjung ulang atau revisit intention berasal dari dua kata yaitu revisit (kunjung ulang)dan intention (minat). Minat untuk mengunjungi kembali adalah suatu perilaku (behavioral intention) atau keinginan pengunjung untuk kembali, dimana pengunjung menyampaikan reputasi dan persepsi positif terhadap kualitas layanan yang baik, yang dapat mengarah pada tindakandimasa yang akan datang [1].Ketertarikan untuk melakukan kunjungan ulang dinyatakan sebagai keinginan akan rekomendasi, yaitu wisatawan mengungkapkan keinginannya untuk kembali dengan merekomendasikannya kepada rekan-rekannya, sebagai kepuasan terhadap destinasi yang dikunjungi [2].

Revisit intention dinilai dari 2 indikator yaitu minat untuk berkunjung ulang dan dan minat untuk merekomendasikan [3]. Terdapat 4 faktor yang mempengaruhi minat kunjung ulangyaitu motivasi perjalanan (travel motivation), pengalaman masa lalu (past experience), kendala yang dirasakan (perceived constraint), dan sikap (attitude) [3].

Permasalahan yang ditemukan di Pantai Air ManisPadang terkait denganrevisit intention adalah wisatawan menyatakan tidak berminat untuk berkunjung kembali karena tidak tercapainya harapan, keinginan, dan kepuasan wisatawan di Pantai Air Manis Padang. Temuan pra penelitian ini didukung dengan tingkat kunjungan wisatawan ke Pantai Air Manis Padang yang menurun di tahun 2020. Pihak pengelola Pantai Air Manis Padangperlu memperhatikan faktor-faktor yang mempengaruhi niat berkunjung ulang. Salah satu faktor minat kunjung ulang adalah past experience. Pengunjung akandatang kembali ke objek wisata apabila pengalaman masa lalu yang dirasakan sesuai dengan harapan wisatawan saat berkunjung.

Memorable tourism experience merupakan kesan pengunjung tentang objek wisata yang terus diingat pascaberkunjung [4]. Pengalaman berwisata menjadi berkesan jika pengalaman yang didapatkan berksesan oleh wisatawan dan terus diingat oleh wisatawan dalam durasi yang lama, maka bisa dikatakan wisatawan tersebut sudah mencapai memorable tourism experience selama mengunjungi objek wisata [4]. Pengelola wisata harus memajukan objek wisata agar dapat memuaskan wisatawan sehingga menjadi pengalaman yang berkesan dengan cara memperhatikan indikator memorable tourism experienceyaitu hedonism (kesenangan), novelty (pengalaman baru), local culture (budaya lokal), refleshment (kesegaran), meaningfulness (arti penting), involvement 164 
(keterlibatan), dan knowledge (pengetahuan)[5].Jika objek wisata dapat memenuhi aspekmemorable tourism experiencemakatingkat keinginan wisatawan untuk kembali berkunjung ke tempat wisata tersebut menjadi tinggi.

Berdasarkan pengamatan dari situs ulasan Google, ditemukan beberapa masalah terkait dengan kesan wisatawan seperti objek wisata Pantai Air Manis Padang kurang menyenangkan karena terdapat banyak sampah disekitar area objek wisata sehingga mempengaruhi pemandangan, adanya pungutan liar diarea objek wisata, tempat wisata terasa membosankan karena atraksi wisata yang sedikit, dan tidak ramahnya penjual di sekitar objek wisata. Permasalahan tersebut mempengaruhi pengalaman wisatawan yang mengesankan (memorable tourism experience).

\section{METODOLOGI}

Penelitian ini merupakan penelitian kuantitatif pendekatan assosiatif kausal. Penelitian assosiatif yaitu rumusan masalah penelitian yang bersifat menanyakan hubungan dua variabel atau lebih [6]. Teknik survei berbentuk angket yang disebarkan kepada sampel penelitian yaitu wisatawan Pantai Air Manis Padang dengan memakai teknik purposive sampling. Purposive sampling adalah cara menentukan sampel dengan alasan tertentu [6]. Didapatkan jumlah sampel 98 orang, jumlah responden tersebut diakui sudah representatif karena jumlah sampel lebih dari batas minimal yaitu sebanyak 30 responden. Teknik analisis datadibantu dengan menggunakan program SPSS 20.00. Uji yang digunakan ialah uji persyaratan analisis dilakukan dengan uji normalitas, uji homogenitas, dan uji linearitas. Pengujian hipotesis penelitian menggunakan analisis regresi linear sederhana.

\section{HASIL DAN PEMBAHASAN}

\section{A. Hasil Penelitian}

Berdasarkan pengujian variabel (X) memorable tourism experience, berupa angket yang disebarkan kepada 98 responden yang dimana validitas dan reliabilitasnya telah memenuhi syarat.Jumlah pernyataan yang diberikan sebanyak 21 butir yang diisi oleh sejumlah responden.Adapun hasil dari olahan data yang telah dilakukan dari penelitian terkait dengan variabel memorable tourism experiencedi Pantai Air Manis Padang adalah sebagai berikut:

Tabel 1. Data Variabel Memorable Tourism Experience

\begin{tabular}{|c|c|c|c|}
\hline Kategori & Kelas Interval & Frekuensi & $\mathbf{( \% )}$ \\
\hline Sangat Baik & $\geq 84,45$ & 0 & $0 \%$ \\
\hline Baik & $70,15-<84,45$ & 14 & $15 \%$ \\
\hline Kurang Baik & $\mathbf{5 5 , 8 5 - < 7 0 , 1 5}$ & $\mathbf{5 0}$ & $\mathbf{5 1 \%}$ \\
\hline Tidak Baik & $41,55-<55,85$ & 34 & $35 \%$ \\
\hline Sangat Tidak Baik & $<41,55$ & 0 & $0 \%$ \\
\hline \multicolumn{2}{|r|}{ Total } & $\mathbf{9 8}$ & $\mathbf{1 0 0 \%}$ \\
\hline
\end{tabular}

Dilihat dari tabel diatas, diketahui bahwa variabel memorable tourism experience (X) sebanyak $0 \%$ responden termasuk dalam kategori sangat baik, 15\% menunjukkan kategori baik, 51\% menunjukkan kategori kurang baik, 35\% menunjukkan kategori tidak baik, dan 0\% menunjukkan kategori sangat tidak baik.

Selanjutnya untuk hasil uji pada variabel revisit intention (Y), dengan angket yang memiliki 8 butir pernyataan yang telah diuji validitas dan reabilitasnya yang kemudian diisi oleh 98 responden. Maka didapatkan hasil penelitian sebagai berikut: 
Tabel 2. Data Variabel Revisit Intention

\begin{tabular}{|c|c|c|c|}
\hline Kategori & Kelas Interval & Frekuensi & $\mathbf{( \% )}$ \\
\hline Sangat Baik & $\geq 31,95$ & 1 & $1 \%$ \\
\hline Baik & $26,65-<31,95$ & 31 & $32 \%$ \\
\hline Kurang Baik & $\mathbf{2 1 , 3 5 - < 2 6 , 6 5}$ & $\mathbf{4 2}$ & $\mathbf{4 3 \%}$ \\
\hline Tidak Baik & $16,05-<21,35$ & 18 & $18 \%$ \\
\hline Sangat Tidak Baik & $<16,05$ & 6 & $6 \%$ \\
\hline \multicolumn{2}{|r|}{ Total } & $\mathbf{9 8}$ & $\mathbf{1 0 0 \%}$ \\
\hline
\end{tabular}

Dari tabel tersebut disimpulkan variabel revisit intention $(\mathrm{Y})$ sebanyak $1 \%$ menunjukkan kategori sangat baik, 32\% menunjukkan kategori baik, 43\% menunjukkan kategori kurang baik, $18 \%$ menunjukkan kategori tidak baik, dan $6 \%$ menunjukkan kategori sangat tidak baik.

Selanjutnya uji persyaratan analisis memorable tourism experience terhadap revisit intention, maka didapatkan hasil sebagai berikut:

1. Hasil uji normalitas untuk variabel memorable tourism experience sebesar 0.617 dan revisit intention 0.095 . Uji yang telah dilakukan, dengan nilai signifikan > dari 0,05 maka disimpulkan kedua data terdistribusi normal.

2. Hasil uji homoogenitas diperoleh angka sig senilai 0.237 dengan taraf signifikansi $\geq 0.05$. dapat dikatakan bahwa signifikansi data besar dari taraf signifikansi. Jadi diartikan data didapat dari populasi yang memiliki variance yang sama atau homogen.

3. Hasil uji linear diperoleh nilai signifikan 0.593 dimana nilai yang tertera melebihi 0.05. Disimpulkan bahwa terdapat hubungan linear yang signifikan antara memorable tourism experience $(\mathrm{X})$ terhadap revisit intention $(\mathrm{Y})$.

Pengujian hipotesis pada Penelitian ini dapat dilihat dari tabel berikut:

Tabel 3. Nilai Signifikansi

ANOVA $^{\mathrm{a}}$

\begin{tabular}{|l|r|r|r|r|r|}
\hline Model & Sum of Squares & \multicolumn{1}{c|}{ df } & Mean Square & \multicolumn{1}{c|}{ F } & Sig. \\
\hline Regression & 244.546 & 1 & 244.546 & 15.976 & $.000^{\mathrm{b}}$ \\
1 Residual & 1469.505 & 96 & 15.307 & & \\
Total & 1714.051 & 97 & & & \\
\hline
\end{tabular}

a. Dependent Variable: Total.Y

b. Predictors: (Constant), Total.X

Bersumber pada hasil uji anova penelitian ini, didapatkan nilai frekuensi 15.976 dengan tingkat signifikansi sebesar $0.000<0.05$, dapat dijelaskanbahwa variabel memorable toursim experience berpengaruh signifikan terhadap variabel revisit intention, maka bisa dikatakan $\mathrm{Ha}$ diterima dan Ho ditolak.

Tabel 4. Koefisiensi Regresi Variabel X Terhadap Variabel Y Coefficients $^{\mathrm{a}}$

\begin{tabular}{|c|c|c|c|c|c|}
\hline \multirow[t]{2}{*}{ Model } & \multicolumn{2}{|c|}{$\begin{array}{l}\text { Unstandardized } \\
\text { Coefficients }\end{array}$} & $\begin{array}{l}\text { Standardized } \\
\text { Coefficients }\end{array}$ & \multirow[t]{2}{*}{$\mathrm{T}$} & \multirow[t]{2}{*}{ Sig. } \\
\hline & $\mathrm{B}$ & Std. Error & Beta & & \\
\hline (Constant) & 13.249 & 2.762 & & 4.798 & .000 \\
\hline Total.X & .181 & .045 & .378 & 3.997 & .000 \\
\hline
\end{tabular}

a. Dependent Variable: Total.Y 
Berdasarkan persamaan diatas didapat koefisien regresi0.181 dengan nilai sig 0,000< 0,05. Maknanya setiap penambahan satuan memorable tourism experience akan menambahkan 0.181 satuan revisit intention.

Tabel 5. R Square Variabel $X$ terhadap Variabel $Y$ Model Summary

\begin{tabular}{|l|r|r|r|r|}
\hline Model & \multicolumn{1}{|c|}{$\mathrm{R}$} & R Square & $\begin{array}{c}\text { Adjusted R } \\
\text { Square }\end{array}$ & $\begin{array}{c}\text { Std. Error of } \\
\text { the Estimate }\end{array}$ \\
\hline 1 & $.378^{\mathrm{a}}$ & .143 & .134 & 3.912 \\
\hline
\end{tabular}

a. Predictors: (Constant), Total.X

Dilihat dari nilai $\mathrm{R}$ square 0.143 , maknanya memorable tourism experience (X) berpengaruh sebesar 14,3\% terhadap revisit intention (Y) di Pantai Air Manis Padang dan 85,7\% dipengaruhi oleh faktor lain.

\section{B. Pembahasan}

\section{Memorable Tourism Experience}

Berdasarkan hasil penilaian dari 98 sampel, untuk variabel memorable tourism experiencedigolongkan pada kategori kurang baik dengan presentase 51\%.Memorable tourism experiencemerupakan kegiatan perjalanan wisata yang dilakukan wisatawan yang menciptakan kesan baik dan perasaan puas dengan perjalanan wisata tersebut sehingga selalu diingat dalam memori dan tidak mudah dilupakan oleh wisatawan setelah mengunjungi tempat wisata tersebut.Kenangan bahagia memberikan emosi positif dan perasaan senang kepada seseorang yang berkedudukan penting di kehidupan seseorang [7].

Berikutnya hasil uraian data setiap indikator yaitu: 1) hedonism (kesenangan) termasuk pada kategori kurang baik pada persentase $27 \%, 2$ ) novelty (pengalaman baru) tergolong dikategori kurang baik dengan persentase $44 \%, 3$ ) local culture (budaya lokal) diposisikan pada kategori kurang baik dengan persentase 35\%, 4) refreshment (perasaan segar) berada pada kategori kurang baik dengan persentase 55\%, 5) meaningfulness (arti penting) berada pada kategori kurang baik dengan presentase 42\%, 6) involvement (keterlibatan) digolongkan ke kategori kurang baik dengan presentase 36\%, dan 7) knowledge (pengetahuan) berada pada kategori kurang baik $47 \%$.

Penelitian ini juga sejalan dengan pendapatlain yang menyatakan bahwaobjek wisata mampu bersaing di usaha wisata jikaobjek wisata dapat memberikan "tourism experience" yang berkesan bagi wisatawan[4].Berdasarkan penjelasan diatas, variabel memorable tourism experience di Pantai Air Manis Padang berada pada kategori kurang baik. Diharapkan dengan adanya penelitian ini dapat memberi gambaran atau masukan bagi pengelola Pantai Air Manis Padang untuk meningkatkan dan mengembangkan objek wisata agar dapat memberikan pengalaman yang berkesan (memorable toursim experience) bagi wisatawan.

\section{Revisit Intention}

Berdasarkan hasil penelitianpada 98 responden, untuk variabel revisit intention digolongkan pada kategori kurang baik dengan presentase 43\%.Revisit intention ialah peluang wisatawan untuk mengulangi kegiatan atau mengunjungi ulang suatu destinasi[8]. Niat berkunjung kembali merupakan salah satu hal yang penting dan niat berkunjung kembali juga merupakan komponen kunci, dan berpengaruh keuntungan dimasa depan [9]. 
Berikutnya hasil deskripsi data setiap indikator yaitu: 1) intention to revisit (minat berkunjung ulang) termasuk pada kategori kurang baik dan hasil persentase 42\%, dan 2) intention to recommend (minat untuk merekomendasikan) berada pada kategori kurang baik dengan persentase $42 \%$. Pada hasil penelitian tentang revisit intention di Pantai Air Manis Padang secara keseluruhan dikategorikan kurang baik. Dapat disimpulkan bahwa minat wisata untuk berkunjung ulang dan minat merekomendasikan kurang tinggi/baik. Kesan negatif wisatawan kepada layananyang disediakan oleh pengelola objek wisata bisa menjadi negative word of mouth (kata negatif dari mulut ke mulut), bahkan tidak adawisatawan yang datang kembali,dapat diartikan loyalitas wisatawan menjadi turun[10]. Diharapkan dengan adanya penelitian ini dapat memberi gambaran atau masukan bagi Pantai Air Manis Padanguntuk meningkatkan revisit intention (minat kunjung ulang)agar menjadi lebih baik dan meningkat.

\section{Pengaruh Memorable Toursim Experience Terhadap Revisit Intention di Objek Wisata Pantai Air Manis Padang}

Hasil uji hipotesis untuk mengetahui derajat kontribusi antara memorable toursim experience terhadap revisit intention di Pantai Air Manis Padang, didapatkan hasil persamaan koefisien regresi0.181 dengan nilai sig. $0.000<0.05$. Maksudnya ialah setiap penambahan 1 satuan memorable tourism experienceakan menambahkan 0.181 revisit intention. Nilai signifikansi didapatkan nilai Fyaitu 15.976dengan tingkat signifikansi0.000 $<0.05$, maknanya memorable toursim experience $(\mathrm{X})$ berpengaruh signifikan terhadap revisit intention (Y). Berikutnya diperoleh nilai $\mathrm{R}$ Square0.143, maknanya variabel memorable tourism experience berpengaruh sebesar 14,3\% terhadap revisit intention di Pantai Air Manis Padang dan 85,7\% dipengaruhi oleh faktor lain. Penelitian ini sejalan dengan pendapat seorang peneliti dalam penelitiannya yang menyatakanbahwa tourism experience berpengaruh signifikan terhadap revisit intention [9]. Hasil penelitian diatas dinyatakan bahwa terdapat pengaruh kontribusi yang signifikan antara memorable tourism experience terhadap revisit intention(minat kunjung ulang) di Pantai Air Manis Padang. Maka memorable tourism experience (pengalaman yang berkesan) memiliki peran penting dalam memajukan peningkatan minat kunjung ulang.

\section{KESIMPULAN}

Dari hasil pengolahan data dan pembahasan yang telah dilakukan, maka dapat ditarik kesimpulan sebagai berikut :

1. Memorable tourism experience pada objek wisata Pantai Air Manis Padang menunjukkan sebagian besar dengan nilai persentase $51 \%$ berada pada 55,85 $<70,15$ tergolong kategori kurang baik.

2. Revisit intention pada objek wisata Pantai Air Manis Padang menunjukkan sebagian besar dengan nilai persentase $43 \%$ berada pada 21,35 < 26,65 tergolong kategori kurang baik.

3. Terdapat pengaruh yang signifikan antara memorable tourism experienceterhadap revisit intentionsebesar 14,3\% terhadap revisit intention di Pantai Air Manis Padang dan 85,7\% dipengaruhi oleh variabel lain. 


\section{DAFTAR PUSTAKA}

[1] N. A. Fadiryana and S. Chan, "Pengaruh Destination Image Dan Tourist Experience Terhadap Revisit Intention Yang Dimediasi Oleh Perceived Value Pada Destinasi Wisata Halal Di Kota Banda Aceh," J. Manaj. Inov., vol. 10, no. 2, pp. 1-23, 2020.

[2] A. Nisa, L. Nabila, S. Armida, J. P. Ekonomi, F. Ekonomi, and U. N. Padang, "Pengaruh Customer Perceived Value dan Customer Experience Terhadap Revisit Intention pada Objek Wisata The Great Wall of Koto Gadang," vol. 3, no. 3, pp. 477-487, 2020.

[3] A. D. I. Finardi and Y. Yuniawati, "Gunung Tangkuban Perahu Pengaruh Customer Experience Terhadap Revisit Intention Di,” Tour. Hosp. Essentials J., vol. 6, no. 1, pp. 983994, 2016.

[4] S. A. dan A. R. Ardiansyah Muhammad, "PENILAIAN MEMORABLE TOURISM EXPERIENCE SEBAGAI FAKTOR PENENTU DAYA SAING DESTINASI WISATA DENGAN MENGGUNAKAN PENDEKATAN RAPID APPRAISAL (RAP)," J. Ilm. Manaj., vol. 8, no. 2, pp. 272-291, 2018.

[5] Verinita, "Pengukuran Memorable Tourism Experience Scale (MTES) Dengan Pendekatan Kim Ritchie Mccormick Untuk Meningkatkan Intensi Berkunjung Kembali Ke Desa Wisata Rantih Kota Sawahlunto Provinsi Sumatera Barat," Pros. Semin. Nas. ASBIS, Politek. Negeri Banjarmasin, pp. 429-450, 2016.

[6] Sugiyono, Metode Penelitian Kuantitatif. Bandung: Alfabeta, 2018.

[7] Ahmad Zulfi Utama, "Peran Dimensi Memorable Tourism Experience (MTE) Dalam Upaya Meningkatkan Intensi Berkunjung Kembali Ke Desa Wisata Sumber Maron,” pp. 68-70, 1377.

[8] R. Kusherdyana, S. Muslim, and H. Soesanto, "The Contribution Of Tourist Experience Towards Tourists Revisit Intention At Seribu Island In DKI Jakarta,” Tour. Sci. J., vol. 5, no. 2, pp. 133-147, 2020.

[9] R. Setiawan and D. A. Kurniawan, "Analisis Tourist Experience Terhadap Revisit Intention pada Objek Wisata Air Panas Se Kabupaten Garut,” Bus. Innov. Entrep. J., vol. 1, no. 3, pp. 175-180, 2019, doi: 10.35899/biej.v1i3.70.

[10] Y. P. Setiyariski Ramdani,Syarifuddin,Didin Kristiutami, "Membangun Nilai Behavioral Intention Melalui Tourist Experience (Studi Tentang Tourist Experience Dampaknya Terhadap Behavioral Intention di Floating Market Lembang)," J. media wisata, vol. 1, no. 1, pp. 25-34, 2019. 